\title{
Estudo da qualidade e quantidade da água em microbacia, afluente do rio Paraíba do Sul - São Paulo, após ações de preservação ambiental
}

(http://dx.doi.org/10.4136/ambi-agua.987)

\author{
Lívia Alves Alvarenga ${ }^{1}$; Maria Paulete Pereira Martins ${ }^{1}$; Luz Adriana Cuartas ${ }^{2}$; \\ Vinicius Alves Penteado ${ }^{3}$; Alexandra Andrade ${ }^{3}$ \\ ${ }^{1}$ Programa de Pós-Graduação em Meteorologia, \\ Instituto Nacional de Pesquisas Espaciais (INPE), São José dos Campos-SP, \\ ${ }^{2}$ Programa de Pós-Graduação em Ciência do Sistema Terrestre, \\ Instituto Nacional de Pesquisas Espaciais (INPE), São José dos Campos-SP, \\ ${ }^{3}$ Instituto Oikos de Agroecologia, Lorena-SP, \\ e-mails: livia.alvarenga@posgrad.ufla.br,maria.paulete@cptec.inpe.br, adriana.cuartas@inpe.br, \\ vinni_alves@yahoo.com.br, andrade.alexandra@uol.com.br
}

\section{RESUMO}

Cada vez mais são necessários programas de monitoramento da qualidade e quantidade da água como subsídios para avaliar as condições dos mananciais e, além disso, propiciar informações para a tomada de decisão com relação ao gerenciamento dos recursos hídricos. Este estudo analisou a qualidade e quantidade da água na microbacia do Ribeirão dos Macacos, afluente do rio Paraíba do Sul, Estado de São Paulo, por meio do monitoramento dos parâmetros: temperatura, $\mathrm{pH}$, condutividade e oxigênio dissolvido, em cinco pontos da microbacia. As medições de vazão e altura da lâmina d' água durante os períodos seco e úmido dos anos de 2010/2011, permitiram obter a "curva chave" em quatro pontos de monitoramento da qualidade da água e reconstruir as séries de vazões para estes períodos. Os resultados das análises mostraram que há um indicativo de mudanças nos parâmetros de qualidade da água devido às práticas conservacionistas adotadas. $\mathrm{O}$ parâmetro temperatura da água foi o mais influenciado pela sazonalidade da vazão. Diversos fatores físicos podem ter contribuído na correlação dos outros parâmetros com a vazão principalmente as diferentes ações de recuperação ambiental implantadas na área deste estudo e que visam uma maior sustentabilidade dos recursos hídricos.

Palavras-chave: práticas conservacionistas, sustentabilidade, parâmetros de qualidade da água e vazão.

\section{Study of the quality and quantity of waters of a tributary watershed of Paraíba do Sul river- São Paulo, after environmental preservation actions}

\begin{abstract}
Monitoring programs of water quality and quantity are necessary to provide subsidies to assess the conditions of the watersheds and for decision making regarding to the management of water resources. This study analyzed the quality and quantity of waters of the Macacos stream watershed, a tributary of the Paraíba do Sul river, in São Paulo State, by monitoring the parameters: temperature, $\mathrm{pH}$, conductivity and dissolved oxygen at five sites in the watershed. The measurements of flow and height of water depth during dry and wet seasons of 2010 and 2011 allowed the construction of the "rating curve" in four points of water quality
\end{abstract}


monitoring and to reconstruct the series of water flow in these seasons. The analysis results showed that there is indication of changes in water quality parameters due to the conservation practices adopted. The water temperature parameter was the most influenced by the seasonal variation in runoff. Several physical factors may have influenced the correlation of the other parameters with runoff, especially the different environmental recovery actions implemented in the study to achieve the sustainability of the water resources.

Keywords: conservation practices, sustainability, water quality parameters and flow.

\section{INTRODUÇÃO}

Os diferentes processos que acontecem em uma bacia dependem das características do local onde ela se insere. Flora, fauna, relevo, uso e ocupação do solo, e os fenômenos meteorológicos, interagem entre si e condicionam a resposta hidrológica na bacia. As diferentes ações antrópicas em determinadas áreas transformam as estruturas físico-químicas e biológicas dos ecossistemas naturais e alteram o ciclo hidrológico, reduzindo desta forma a oferta de água e consequentemente a queda da qualidade dos recursos hídricos. A região do Vale do Paraíba-São Paulo, de grande relevância para o Brasil por ser bastante desenvolvida economicamente, apresenta um grande contingente populacional e sérios problemas ambientais. Assim, é uma região na qual são necessárias diferentes ações voltadas para a recuperação e preservação dos recursos naturais.

Manandhar et al. (2011), em estudo feito no Nepal, centrado nas percepções e adaptações dos agricultores às mudanças climáticas, salientou que há uma necessidade de se ir além do nível individual, para planejar e fornecer apoio de tecnologias apropriadas e estratégias a fim de lidar com os esperados crescentes impactos das mudanças do clima. Desta maneira, tornase fundamental o incentivo a gestão agrícola sustentável e a difusão de práticas tecnológicas de baixo custo.

Conforme Marengo e Alves (2005), no estudo das tendências hidrológicas na bacia do rio Paraíba do Sul (para o período de 1920-2000), é evidente que o progressivo processo de industrialização e urbanização assim como a degradação ambiental no Vale do Rio Paraíba do Sul, contribuem para o intenso uso dos recursos naturais e para o comprometimento da qualidade e quantidade dos recursos hídricos hoje observados. Estes autores registraram tendências decrescentes nas vazões do rio em vários postos e dentre as possíveis causas, apontadas pelos autores, desta redução sistemática nas vazões e cotas tem-se as atividades antrópicas, que também estão associadas às mudanças gradativas no regime e distribuição de chuvas na bacia, decorrentes de mudanças climáticas regionais.

De acordo com Machado et al. (2010) torna-se de fundamental importância implementar e identificar medidas no sentido de melhorar a qualidade da água, contribuindo deste modo para a elaboração dos Planos de Gestão da Região Hidrográfica. Segundo Golla (2006), o manejo adequado (intervenção humana nos recursos naturais com a intenção de torná-los aptos à utilização agrícola e pecuária, de maneira que preservem características desejáveis às atividades destinadas ao homem) de solos e água constitui um dos grandes desafios da humanidade, estando diretamente relacionados à sustentabilidade de todas as formas de vida, bem como às atividades antrópicas.

Neary et al. (2009) relatam que a maior sustentabilidade e melhoria da qualidade de fontes de água doce do mundo se originam em ecossistemas florestais. As características químicas, biológicas e físicas dos solos florestais são particularmente adequadas para o fornecimento de água de alta qualidade em bacias hidrográficas, moderando o fluxo, e fornecendo diversos habitats aquáticos. Os sistemas radiculares sob florestas são extensos e 
relativamente profundos em relação às terras agrícolas e pastos, e tendem a criar solos com alta macroporosidade, baixa densidade, altas condutividade hidráulica saturada e taxas de infiltração. A conversão de florestas em áreas agrícolas ou urbanas quase sempre resulta na deterioração da qualidade da água. Santos et al. (2011) também reportam que a reposição florestal com matas nativas se constitui em uma das principais formas de aumentar a retenção de água (manutenção da vazão) em uma bacia hidrográfica pelo aumento da infiltração no solo e redução do escoamento superficial e erosão.

A água é um dos elementos mais importantes e fundamentais para a manutenção da vida com qualidade, para o conforto climático, e complementarmente, para o desenvolvimento econômico. Desta maneira, alguns trabalhos já foram realizados associando a qualidade das águas com os diferentes usos do solo, mostrando os efeitos na qualidade ambiental (Bolstad e Swank, 1997; Arcova e Cicco, 1999). Os trabalhos em questão foram realizados respectivamente na América do Norte e América do Sul. Os autores evidenciam os impactos da modificação da paisagem nos parâmetros de qualidade da água e enfatizam que durante eventos de tempestade no período úmido de cada um dos locais de estudo, ocorreu uma maior alteração dos parâmetros de qualidade da água analisados.

Silva et al. (2008), no estudo da influência da precipitação na qualidade da água no rio Purus (afluente do rio Amazonas) também ressaltou que o regime da precipitação em diferentes localidades pode influenciar os valores de qualidade da água. Apesar dos resultados serem preliminares, esta pesquisa mostrou que a precipitação parece ser o principal agente influenciador da qualidade da água do rio Purus, uma vez que foi observado que as variáveis monitoradas se correlacionam significativamente com o regime de chuvas do local.

Silva et al. (2009) mostraram que os seus resultados de qualidade da água no Reservatório da Usina Hidrelétrica (UHE)- Peti - MG, foram divididos em: Época de estiagem (setembro, outubro, abril e maio) e chuvosa (novembro, dezembro, janeiro, fevereiro e março) e, no geral, apresentam variação sazonal (2004-2005). Na época chuvosa, parâmetros como sólidos, turbidez e cor aumentam a concentração; sendo observada também maior variação entre as profundidades na época de estiagem, e à medida que se adentra no reservatório (montante para jusante), parâmetros como turbidez, cor e sólidos totais em suspensão diminuem em função da sua própria dinâmica.

Os autores Bueno et al. (2005) afirmam que o tipo de cobertura vegetal implica em distintos comportamentos nos atributos do solo e da água, sendo que a remoção das florestas tem causado aumento significativo dos processos que levam à degradação de áreas imensas, com prejuízos à hidrologia e à biodiversidade. Este trabalho apresenta o monitoramento da qualidade da água em duas condições de uso do solo (mata nativa e eucalipto), e foi verificado que a cobertura do solo de mata nativa foi responsável pela manutenção da temperatura da água estável, influenciando as demais variáveis da água (OD, $\mathrm{MO}$ e $\mathrm{pH})$. Assim, por meio dos plantios florestais de mata nativa os produtores rurais podem obter benefícios na conservação do solo e da água e reduzir os impactos negativos da redução das vegetações naturais remanescentes.

Neste contexto, propõe-se com este trabalho obter e analisar os dados de qualidade e quantidade de água na microbacia do Ribeirão dos Macacos em período seco e úmido nos anos de 2010 e 2011, por meio do acompanhamento de alguns parâmetros (indicativos de qualidade da água) e da vazão, enfatizando as diferentes práticas de recuperação ambiental, efetuadas pelo Instituto Oikos de Agrecologia na área de monitoramento.

Este estudo faz parte do projeto "Estudo da influência da recuperação e conservação ambiental na melhoria da qualidade e quantidade da água em microbacias do Rio Paraíba do Sul, no estado de São Paulo", financiado pelo Fundo Estadual de Recursos Hídricos 
(FEHIDRO). Este trabalho foi possível devido a uma colaboração entre o Centro de Previsão de Tempo e Estudos Climáticos (CPTEC/INPE) e o Instituto Oikos de Agroecologia.

\section{MATERIAIS E MÉTODO}

A microbacia do ribeirão dos Macacos, afluente do rio Paraíba do Sul, localiza-se no estado de São Paulo, nos municípios de Guaratinguetá e Lorena, entre as coordenadas de $22^{\circ} 38^{\prime} 56,2^{\prime \prime} \mathrm{S}, 45^{\circ} 15,2^{\prime} 2,6^{\prime}$ 'W e $22^{\circ} 42^{\prime} 45,1^{\prime}$ 'S $, 45^{\circ} 6^{\prime} 59,6^{\prime}$ ' $\mathrm{W}$, aproximadamente. A bacia hidrográfica apresenta área de aproximadamente $39 \mathrm{~km}^{2}$, o equivalente a 3900 hectares. No entanto, a área de estudo de monitoramento da qualidade e quantidade de água e acompanhamento das práticas ambientais corresponde a aproximadamente 400 hectares a jusante da microbacia do ribeirão dos Macacos (Figura 1).

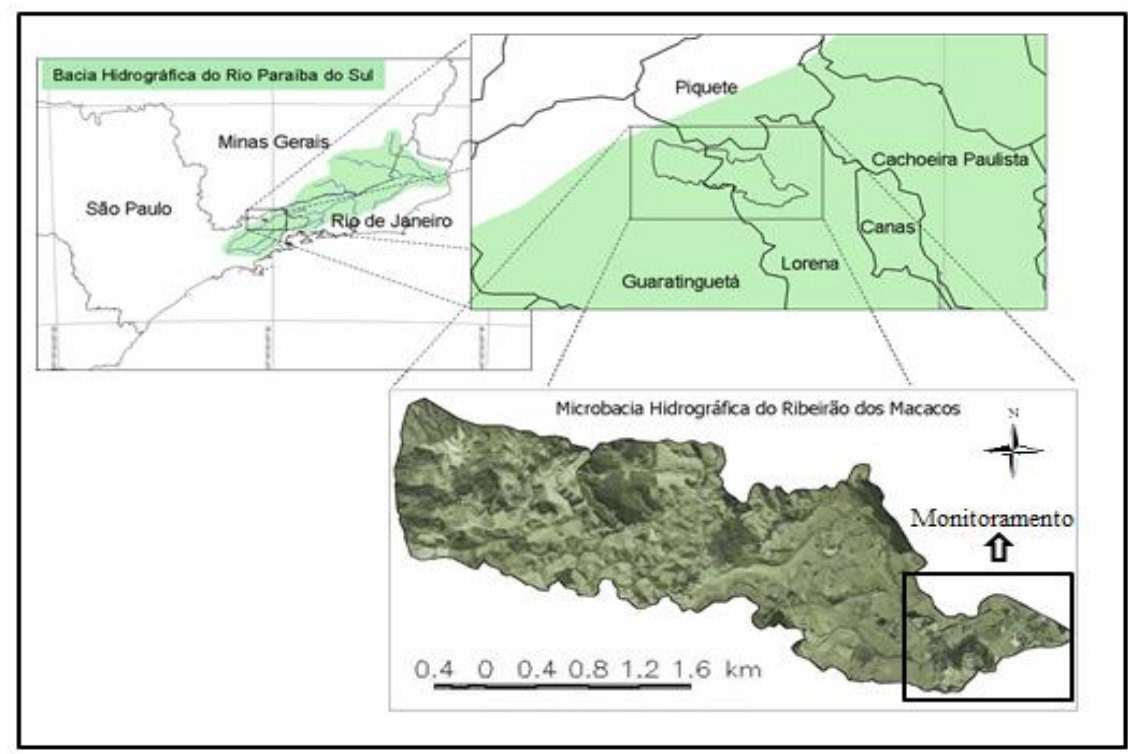

Figura 1. Localização da microbacia do ribeirão dos Macacos-SP entre as coordenadas de $22^{\circ} 38^{\prime} 56,2^{\prime}$ ' $\mathrm{S}, 45^{\circ} 15,2^{\prime} 2,6^{\prime}$ ' $\mathrm{W}$ e $22^{\circ} 42^{\prime} 45,1^{\prime}$ 'S, $45^{\circ} 6^{\prime} 59,6^{\prime}$ 'W (retângulo da parte superior direita).

Fonte: Instituto Oikos de Agroecologia [ca. 2009].

De acordo com Fisch (1995) o clima da região apresenta temperaturas elevadas - média anual de $22^{\circ} \mathrm{C}$ - e duas estações de precipitação bem definidas: uma chuvosa que corresponde ao verão, e outra seca, que corresponde ao inverno. No verão a Zona de Convergência do Atlântico Sul (ZCAS) é um dos principais mecanismos responsável pelo aumento da precipitação (Lima et al., 2010).

O padrão de uso do solo na microbacia do ribeirão dos Macacos é predominantemente rural, sendo a porcentagem de cada uso do solo apresentado na Tabela 1.

Tabela 1. Uso do solo na microbacia do ribeirão dos Macacos.

\begin{tabular}{l|c}
\hline Uso do solo na microbacia & Área (\%) \\
Pastagem & 68,0 \\
Fragmentos florestais & 21,6 \\
Plantio de eucalipto & 5,7 \\
Área urbano industrial & 3,0 \\
Plantações (capineiras e plantios de hortas) & 1,7 \\
\hline
\end{tabular}

Fonte: Instituto Oikos de Agroecologia [ca. 2009]. 
$\mathrm{Na}$ área deste estudo está localizado o Instituto Oikos de Agroecologia, que vem desenvolvendo ações de restauração ambiental, adequação de métodos produtivos, conservação dos recursos naturais (águas e biodiversidade), mobilização e capacitação de produtores rurais (educação ambiental) desde o início de 2009. Assim, por meio de parcerias entre instituições públicas e privadas juntamente com a comunidade local da microbacia do Ribeirão dos Macacos, foi possível o estudo da área e de alguns elementos desta, visando à utilização de práticas sustentáveis do uso dos recursos naturais.

O Instituto Oikos de Agroecologia a partir de questionários aplicados aos proprietários rurais da região selecionou as propriedades mais necessitadas das práticas de recuperação ambiental, com o intuito de eliminar parte das fontes pontuais de contaminação da microbacia. Na Tabela 2 apresentam-se as fazendas e as respectivas ações que ocorreram envolvendo os pontos de monitoramento da qualidade e quantidade (descritos mais adiante) e os proprietários da região (pontos de apoio utilizados).

Tabela 2. Fazendas de atuação do Instituto Oikos de Agroecologia e suas respectivas ações.

\begin{tabular}{|c|c|}
\hline Proprietários & Ações de recuperação \\
\hline Propriedade da Sra. Marisa Nunes $\left(\mathrm{P}_{1}\right)$ & $\begin{array}{l}\text { Instalação de bebedouro para o gado (início: } \\
01 / 06 / 2010 \text { ). }\end{array}$ \\
\hline Propriedade do Sr. José Fernando $\left(\mathrm{P}_{2}\right)$. & $\begin{array}{l}\text { Instalação de bebedouro para o gado (início: } \\
01 / 06 / 2010 \text { ). }\end{array}$ \\
\hline Propriedade do Sr. Fernando Miyazaki $\left(\mathrm{P}_{3}\right)$. & $\begin{array}{l}\text { Implantação de } 2,5 \text { hectares de pastejo } \\
\text { rotacionado "Voisin" (início: 08/09/2009), } \\
\text { instalação de uma chorumeira (início: } \\
\text { 23/06/2010), uma fossa séptica (início: } \\
\text { 09/04/2010) e bebedouro para o gado (início: } \\
\text { 01/06/2010). }\end{array}$ \\
\hline Propriedade do Sr. Darci de Paula $\left(\mathrm{P}_{4}\right)$. & $\begin{array}{l}\text { Implantação de } 2,5 \text { hectares de pastejo } \\
\text { rotacionado "Voisin" (início: 08/09/2009), } \\
\text { Restauração de 1,5 hectares de Áreas de } \\
\text { Preservação Permanente (início: 03/05/2010). }\end{array}$ \\
\hline $\begin{array}{l}\text { Propriedade do Sr. José Raimundo Ferreira } \\
\text { (Ponto de apoio). }\end{array}$ & $\begin{array}{l}\text { Instalação de duas fossas sépticas (início: } \\
\text { 09/04/2010), Limpeza de três fossas negras } \\
\text { (início: 09/04/2010) e instalação de } \\
\text { bebedouro para o gado (início: } 01 / 06 / 2010 \text { ). }\end{array}$ \\
\hline $\begin{array}{l}\text { Propriedade do Sr. Arnaldo Leite (Ponto de } \\
\text { apoio). }\end{array}$ & $\begin{array}{l}\text { Instalação de duas fossas sépticas (início: } \\
\text { 09/04/2010). }\end{array}$ \\
\hline Propriedade da Sra. Regina Nunes. & $\begin{array}{l}\text { Instalação de bebedouro para o gado (início: } \\
01 / 06 / 2010 \text { ). }\end{array}$ \\
\hline Propriedade da Sr. Luiz Domingos Bastos. & $\begin{array}{l}\text { Instalação de bebedouro para o gado (início: } \\
01 / 06 / 2010 \text { ). }\end{array}$ \\
\hline
\end{tabular}

Fonte: Instituto Oikos de Agroecologia [ca. 2009].

Na escolha dos pontos de monitoramento na microbacia do Ribeirão dos Macacos foi levado em consideração o uso e ocupação do solo e as ações que foram realizadas pelo Instituto Oikos de Agroecologia. Os pontos de monitoramento da qualidade da água: $\mathrm{P}_{1}, \mathrm{P}_{3} \mathrm{e}$ $\mathrm{P}_{5}$ estão localizados na entrada, na porção intermediária e na saída da região de monitoramento, respectivamente. Os pontos $\mathrm{P}_{2}$ e $\mathrm{P}_{4}$ estão localizados após nascentes que 
devem ser recuperadas futuramente. A cobertura vegetal de mata ciliar na área de monitoramento é pouco extensa, justificando a necessidade de plantio. Aliás, na área do ribeirão dos Macacos $68 \%$ da microbacia está coberta por pastagens, o que justifica ainda mais ações de recuperação ambiental.

O monitoramento, feito em campo, da qualidade e altura da lâmina d'água na microbacia segundo o Standard Methods (APHA, 1995) é realizado por meio de uma sonda multiparâmetros (YSI 6820) que mede por meio de sensores específicos as seguintes características de qualidade da água: temperatura $\left({ }^{\circ} \mathrm{C}\right)$, potencial hidrogeniônico-pH, condutividade elétrica $\left(\mu \mathrm{S} \mathrm{cm}^{-1}\right)$, oxigênio dissolvido-OD $\left(\mathrm{mg} \mathrm{L}^{-1}\right)$ e altura da lâmina d'água na microbacia $(\mathrm{m})$. Os dados provenientes da sonda multiparâmetros são armazenados em um datalogger, que consiste num sistema de acumulação de dados que se encontra ligado à sonda.

A calibração dos sensores medidores dos parâmetros de qualidade da água foi feita periodicamente no Laboratório de Instrumentação Meteorológica (LIM) do Centro de Previsão de Tempo e Estudos Climáticos (CPTEC) - INPE. As medições dos parâmetros de qualidade da água foram realizadas, em média, uma vez por semana nos cinco pontos escolhidos pelo Instituto Oikos de Agroecologia para o monitoramento. O horário da coleta dos dados foi entre 14:00 e 16:00 horas. Das cinco amostragens realizadas a cada dia, obtémse a média em cada ponto para cada parâmetro monitorado. Os dados obtidos nos anos de 2010/2011 (Junho/2010 até setembro/2011) são analisados, por meio da estatística descritiva (média e desvio padrão), levando-se em consideração o período seco e úmido destes anos.

Para as medições de vazão utilizou-se um método simples de medição indireta também conhecida como "manual". Este método foi utilizado pela falta de equipamento para a realização de medições mais acuradas. Em todos os pontos em que se fez o monitoramento da qualidade da água foram feitas as medições de vazão, exceto no ponto $\mathrm{P}_{2}$, por se tratar de um lago. Este local, muitas vezes serve para dessedentação do gado na região e no período úmido deságua na microbacia.

A velocidade média do fluxo de água foi medida utilizando-se uma bola de isopor colocada num determinado ponto, e depois solta. A distância que a bola de isopor flutuou foi pré-fixada e o tempo percorrido marcado com um cronômetro. A velocidade do fluxo de água foi obtida dividindo-se a distância percorrida pelo tempo. Este procedimento foi repetido três vezes para se obter um valor médio. Conforme Mosley e Mckerchar (1993), as medições da velocidade, por serem do fluxo superficial devem ser corrigidas, pois estas podem estar superestimadas, a velocidade média do fluxo no perfil vertical é $86 \%$ da velocidade na superfície.

Os dados de vazão foram monitorados no período úmido e seco do ano de 2011 (março/2011 até novembro/2011), em intervalos aproximados de 20 dias. Com a relação entre altura da lâmina d'água e a respectiva vazão foi possível obter a curva chave em cada ponto de monitoramento, levando-se em conta as características hidráulicas e geométricas da seção transversal de cada ponto. Com a curva chave foi possível reconstruir as vazões (nos pontos: $\mathrm{P}_{1}, \mathrm{P}_{3}, \mathrm{P}_{4}$ e $\mathrm{P}_{5}$ ) para os anos de 2010 e 2011 durante todo o período do monitoramento da qualidade da água na microbacia.

A correlação entre a vazão e os parâmetros de qualidade da água (temperatura, pH, condutividade elétrica e OD) nos diferentes pontos foi averiguada por meio do coeficiente de correlação de Pearson, que varia de +1 (correlação perfeita positiva) a -1 (correlação perfeita negativa). A correlação de Pearson é um indicador estatístico de precisão que indica o grau de dispersão dos dados estimados em relação à média (Santos, 2007). 


\section{RESULTADOS E DISCUSSÃO}

Os períodos secos deste estudo foram junho, julho e agosto (JJA) dos anos de 2010 e 2011 cuja precipitação acumulada foi de, respectivamente, 77 e $62 \mathrm{~mm}$. O período úmido foi de dezembro, janeiro, fevereiro e março (DJFM) de 2010/2011 com precipitação acumulada de $1231 \mathrm{~mm}$.

A temperatura da água foi medida somente em dois períodos JJA de 2010 e DJFM de 2010/2011, devido a problemas com o sensor da sonda multiparâmetros. Os outros parâmetros de qualidade da água (potencial hidrogeniônico, condutividade elétrica e oxigênio dissolvido) também foram medidos no período seco posterior JJA de $2011 \mathrm{com}$ a finalidade de comparações.

As médias e o desvio padrão (Desv. Pad.) da temperatura da água para os períodos, seco (JJA de 2010) e úmido (DJFM de 2010/2011) nos diferentes pontos $\left(\mathrm{P}_{1}, \mathrm{P}_{2}, \mathrm{P}_{3}, \mathrm{P}_{4}\right.$ e $\left.\mathrm{P}_{5}\right)$ encontram-se na Tabela 3.

Tabela 3. Médias e desvio padrão da temperatura da água $\left({ }^{\circ} \mathrm{C}\right)$ nos diferentes pontos e períodos de estudo.

\begin{tabular}{l|rrrrr}
\hline \multirow{2}{*}{ Pontos } & \multicolumn{5}{c}{ Temperatura $\left({ }^{\circ} \mathbf{C}\right)$} \\
\cline { 2 - 6 } & $\mathrm{P}_{1}$ & $\mathrm{P}_{2}$ & $\mathrm{P}_{3}$ & $\mathrm{P}_{4}$ & $\mathrm{P}_{5}$ \\
\hline \multirow{3}{*}{ Média } & \multicolumn{5}{c}{ Período seco (JJA de 2010) } \\
Desvio Padrão & 17,1 & 20,0 & 16,4 & 17,0 & 16,7 \\
& 1,3 & 1,0 & 1,3 & 1,0 & 1,1 \\
\hline Média & \multicolumn{5}{c}{ Período úmido (DJFM de 2010/2011) } \\
Desvio Padrão & 23,2 & 23,2 & 21,0 & 21,7 & 21,8 \\
\hline
\end{tabular}

Observando-se os dois períodos estudados, as menores temperaturas da água foram encontradas no período seco (inverno no Hemisfério Sul), como esperado. As maiores médias da temperatura da água nos dois períodos estudados foram para os pontos $\mathrm{P}_{1}$ e $\mathrm{P}_{2}$ do monitoramento. Os dados em questão, nos diferentes pontos, apresentaram baixos valores de dispersão (desvio padrão variando de 1,0 até 1,6), o que indica pouca variabilidade dos valores amostrados nos períodos, seco (JJA de 2010) e úmido (DJFM de 2010/2011) estudados.

Os pontos $\mathrm{P}_{1}$ e $\mathrm{P}_{2}$ estão localizados em áreas com menor cobertura florestal próximo as margens quando comparados com os pontos $\mathrm{P}_{3}, \mathrm{P}_{4}$ e $\mathrm{P}_{5}$. A mata ciliar na microbacia confere maior proteção contra o aquecimento da água, devido à menor exposição dos corpos d'água à luz solar direta. Torna-se importante ressaltar que além do ponto $\mathrm{P}_{1}$ outras áreas a montante da região de monitoramento apresentam total falta de mata ciliar. $O$ ponto $P_{2}$ além de apresentar pouca mata ciliar trata-se de um lago, assim, o baixo fluxo das águas faz com que as temperaturas superficiais neste ponto sejam maiores. Desta maneira, a ausência ou pequena quantidade de mata ciliar pode ser responsável pelo maior aquecimento das águas na microbacia. Outros autores como Arcova e Cicco (1999); Bueno et al. (2005) também observaram que a falta de vegetação em uma microbacia é responsável por variações na temperatura da água, podendo interferir em outras variáveis, sugerindo assim a necessidade imprescindível do manejo adequado do solo em microbacias.

Com relação à vazão, foi observado que o ponto $\mathrm{P}_{1}$ apresenta as menores medidas de altura da lâmina d'água (m) quando comparado com os pontos $\mathrm{P}_{3}, \mathrm{P}_{4}$ e $\mathrm{P}_{5}$. Em se tratando de 
largura da seção de cada ponto, em $\mathrm{P}_{1}$ (variando de 2,60 $\mathrm{m}$ até 4,40 $\mathrm{m}$ ) e $\mathrm{P}_{3}$ (variando de 4,00 $\mathrm{m}$ até $5,00 \mathrm{~m}$ ) se têm os maiores valores quando comparado com $\mathrm{P}_{4}$ (variando de $1,45 \mathrm{~m}$ até $2,00 \mathrm{~m}$ ) e $\mathrm{P}_{5}$ (variando de 3,0 $\mathrm{m}$ até 3,5 m). Maier (1987) também destacou que o aquecimento direto da água é diretamente proporcional a área da superfície e, inversamente, a altura da lâmina d'água na microbacia. O aquecimento indireto acontece por meio da insolação no solo e relaciona-se com o tipo de substrato por onde a água escoa. Sendo assim, ambos são influenciados pela fisiografia da bacia de drenagem (geologia, geomorfologia, pedologia e hidrografia), material em suspensão na água e pela vegetação marginal.

Na Tabela 4 são apresentadas as médias e o desvio padrão do potencial hidrogeniônico (pH) da água para os períodos, secos (JJA de 2010 e 2011) e úmidos (DJFM de 2010/2011) nos diferentes pontos $\left(\mathrm{P}_{1}, \mathrm{P}_{2}, \mathrm{P}_{3}, \mathrm{P}_{4}\right.$ e $\left.\mathrm{P}_{5}\right)$. A maioria dos valores de $\mathrm{pH}$ observados encontram-se dentro dos limites estipulados pela CONAMA (Brasil, 2005), que são de 6 a 9. Somente no ponto $\mathrm{P}_{2}$ algumas poucas amostragens apresentaram valores de $\mathrm{pH}$ inferiores a 6,0, o que não é considerado ideal pela CONAMA (Brasil, 2005). Na Tabela 4 as maiores médias de $\mathrm{pH}$ da água nos três períodos estudados são para o ponto $\mathrm{P}_{5}$, porém as médias nos diferentes pontos, em cada um dos períodos são bem próximas.

Tabela 4. Médias e desvio padrão dos dados de potencial hidrogeniônico da água nos diferentes pontos e períodos de estudo.

\begin{tabular}{l|ccccc}
\hline \multirow{2}{*}{\multicolumn{1}{c|}{ Pontos }} & \multicolumn{5}{|c}{ Potencial Hidrogeniônico } \\
\cline { 2 - 6 } & $\mathrm{P}_{1}$ & $\mathrm{P}_{2}$ & $\mathrm{P}_{3}$ & $\mathrm{P}_{4}$ & $\mathrm{P}_{5}$ \\
\hline \multirow{3}{*}{ Média } & \multicolumn{5}{c}{ Período seco (JJA de 2010) } \\
Desvio Padrão & 6,6 & 6,6 & 6,8 & 6,6 & 6,8 \\
\hline \multirow{3}{*}{ Média } & 0,1 & 0,1 & 0,1 & 0,2 & 0,2 \\
Desvio Padrão & \multicolumn{5}{c}{ Período úmido (DJFM de 2010/2011) } \\
\hline \multirow{3}{*}{ Média } & 6,7 & 6,4 & 6,7 & 6,9 & 6,9 \\
Desvio Padrão & 0,2 & 0,4 & 0,2 & 0,6 & 0,5 \\
\cline { 2 - 6 } & 7,3 & 7,1 & 7,4 & 7,4 & 7,5 \\
\cline { 2 - 6 } & 0,2 & 0,4 & 0,3 & 0,3 & 0,3 \\
\hline
\end{tabular}

Nos períodos, seco (JJA de 2010) e úmido (DJFM de 2010/2011) as médias do pH estão bem próximas em todos os pontos (variando de 6,4 até 6,9). Já no período seco posterior (JJA de 2011) as médias nos diferentes pontos indicam maiores valores de $\mathrm{pH}$ quando comparados com os períodos anteriores (variando de 7,1 a 7,5). Os dados em questão, nos diferentes pontos, apresentaram baixos valores de dispersão (desvio padrão variando de 0,1 até 0,6 ), o que indica pouca variabilidade nos valores amostrados nos períodos, seco (JJA de 2010), úmido (DJFM de 2010/2011) e seco (JJA de 2011) estudados.

Com relação à condutividade elétrica da água $\left(\mu \mathrm{S} \mathrm{cm}^{-1}\right)$ nos períodos, seco (JJA de 2010) e úmido (DJFM de 2010/2011) as médias foram mais aproximadas nos diferentes pontos (variando de 34,0 até $50,1 \mu \mathrm{S} \mathrm{cm} \mathrm{cm}^{-1}$ ). Já no período seco posterior (JJA de 2011) as médias nos diferentes pontos indicam valores menores quando comparados com os períodos anteriores (variando de 26,0 até 27,1 $\mu \mathrm{S} \mathrm{cm}^{-1}$ ) (Tabela 5). No período úmido (DJFM de 2010/2011), os dados nos diferentes pontos apresentam os maiores valores de dispersão (desvio padrão variando de 9,3 até 12,5), o que indica maior variabilidade nos valores amostrados neste período quando comparado aos dois períodos secos estudados. 
Tabela 5. Médias e desvio padrão dos dados de condutividade elétrica da Água $\left(\mu \mathrm{S} \mathrm{cm}^{-1}\right)$ nos diferentes pontos e períodos de estudo.

\begin{tabular}{l|ccccc}
\hline \multirow{2}{*}{ Pontos } & \multicolumn{5}{|c}{ Condutividade $(\boldsymbol{\mu S}$ cm-1) } \\
\cline { 2 - 6 } & $\mathrm{P}_{1}$ & $\mathrm{P}_{2}$ & $\mathrm{P}_{3}$ & $\mathrm{P}_{4}$ & $\mathrm{P}_{5}$ \\
\hline \multirow{2}{*}{ Média } & \multicolumn{5}{c}{ Período seco (JJA de 2010) } \\
Desvio Padrão & 42,8 & 40,4 & 42,2 & 42,4 & 41,0 \\
& 4,9 & 2,2 & 6,9 & 5,7 & 5,1 \\
\hline \multirow{3}{*}{ Média } & \multicolumn{5}{c}{ Período úmido (DJFM de 2010/2011) } \\
Desvio Padrão & 39,4 & 34,6 & 47,2 & 34,0 & 50,1 \\
\hline \multirow{2}{*}{$\begin{array}{l}\text { Média } \\
\text { Desvio Padrão }\end{array}$} & 12,5 & 11,8 & 9,3 & 11,6 & 11,5 \\
& 26,3 & 26,0 & 26,8 & 27,1 & 27,0 \\
& 4,6 & 6,3 & 4,3 & 4,5 & 4,6 \\
\hline
\end{tabular}

Segundo a CONAMA (Brasil, 2005) para águas doces de classe 2, o oxigênio dissolvido (OD) não deve ser inferior a $5 \mathrm{mg} \mathrm{L} \mathrm{L}^{-1}$. Algumas amostragens na microbacia apresentaram valores abaixo desse valor estipulado (Tabela 6), principalmente no ponto $\mathrm{P}_{5}$, apresentando os menores valores médios. Os dados em questão, nos diferentes pontos no período úmido apresentaram os maiores valores de dispersão (desvio padrão variando de 0,6 até 1,0), o que indica maior variabilidade nos valores amostrados neste período quando comparados aos dois períodos secos estudados. Observa-se também que o oxigênio dissolvido ( $\left.\mathrm{mg} \mathrm{L}^{-1}\right)$ nos diferentes pontos apresenta valores médios aproximados nos períodos, seco (JJA de 2010) e úmido (DJFM de 2010/2011) (variando de 3,6 até 5,5 $\mathrm{mg} \mathrm{L}^{-1}$ ). Já no período seco posterior (JJA de 2011) as médias de OD nos diferentes pontos indicam maiores valores quando comparados com os períodos anteriores (variando de 5,0 até $6,2 \mathrm{mg} \mathrm{L}^{-1}$ ). As médias menores no período úmido (DJFM de 2010/2011) em relação ao período seco (JJA de 2011) estudados podem ser devido ao maior total de precipitação na área, que ocasiona erosão, lixiviamento dos solos e consequentemente maior fluxo de substâncias para dentro da microbacia. Desta maneira um acréscimo do efluente agropecuário na microbacia pode ter contribuído para diminuição do OD no período úmido (DJFM de 2010/2011) em relação ao período seco (JJA de 2011).

Alguns autores verificaram a variabilidade do OD associada a outros fatores. Nos trabalhos de Arcova e Cicco (1999); Silva et al. (2009), foi observado que as menores temperaturas da água na microbacia (período seco do ano) estão diretamente ligadas as maiores concentrações de Oxigênio Dissolvido, e que menores declividades de canais podem proporcionar menores concentrações de OD na água. Maier (1987) também ressaltou que em águas correntes, sob circunstâncias normais, o conteúdo de OD é alto e varia ao longo do rio, devido a alterações em suas características ambientais e em consequência das condições climáticas. Este autor enfatizou que como a solubilidade do OD é inversamente proporcional à temperatura, seu teor tende a diminuir pelo aquecimento das águas durante o dia e aumentar pelo resfriamento no período noturno. 
Tabela 6. Médias e desvio padrão dos dados de oxigênio dissolvido da água $\left(\mathrm{mg} \mathrm{L}^{-1}\right)$ nos diferentes pontos e períodos de estudo.

\begin{tabular}{|c|c|c|c|c|c|}
\hline \multirow{2}{*}{ Pontos } & \multicolumn{5}{|c|}{ Oxigênio Dissolvido $\left(\mathrm{mg} \mathrm{L}^{-1}\right)$} \\
\hline & $\mathrm{P}_{1}$ & $\mathrm{P}_{2}$ & $\mathrm{P}_{3}$ & $\mathrm{P}_{4}$ & $\mathrm{P}_{5}$ \\
\hline & \multicolumn{5}{|c|}{ Período seco (JJA de 2010) } \\
\hline Média & 5,2 & 5,1 & 4,8 & 4,9 & 4,9 \\
\hline \multirow[t]{2}{*}{ Desvio Padrão } & 0,4 & 0,9 & 0,4 & 0,3 & 0,3 \\
\hline & \multicolumn{5}{|c|}{ Período úmido (DJFM de 2010/2011) } \\
\hline Média & 5,0 & 5,5 & 5,5 & 4,8 & 3,6 \\
\hline \multirow[t]{2}{*}{ Desvio Padrão } & 1,2 & 1,2 & 0,9 & 0,5 & 0,9 \\
\hline & \multicolumn{5}{|c|}{ Período seco (JJA de 2011) } \\
\hline Média & 6,2 & 5,4 & 5,5 & 5,8 & 5,0 \\
\hline Desvio Padrão & 0,6 & 0,9 & 0,7 & 0,6 & 1,0 \\
\hline
\end{tabular}

Por se tratar de uma área em que ações de preservação e reconstituição do ambiente natural da microbacia têm sido empregadas, desde 2009, pelo Instituo Oikos de Agroecologia, torna-se importante destacar alguns índices observados no decorrer deste estudo. Quando se compara o primeiro período seco (JJA de 2010) com o seguinte período seco (JJA de 2011), em todos os pontos estudados, pode-se observar no ano de 2011 uma leve tendência de aumento médio no potencial hidrogeniônico-pH e oxigênio dissolvido-OD ( $\left.\mathrm{mg} \mathrm{L}^{-1}\right)$, e um decaimento médio da condutividade elétrica $\left(\mu \mathrm{S} \mathrm{cm}^{-1}\right)$.

$\mathrm{Na}$ Tabela 7 se encontram as médias e o desvio padrão das vazões reconstruídas por meio das curvas chaves $\left(\mathrm{P}_{1}: \mathrm{Q}=22,07 \mathrm{~h}^{2}-11,60 \mathrm{~h}+1,858, \mathrm{R}^{2}=0,979 ; \mathrm{P}_{3}: \mathrm{Q}=0,786 \mathrm{~h}^{2}-0,276 \mathrm{~h}+0,769\right.$; $\mathrm{R}^{2}=0,808 ; \mathrm{P}_{4}: \mathrm{Q}=0,395 \mathrm{~h}^{2}+0,379 \mathrm{~h}+0,262, \mathrm{R}^{2}=0,891$ e $\mathrm{P}_{5}: \mathrm{Q}=8,56 \mathrm{~h}^{2}-2,332 \mathrm{~h}+0,179, \mathrm{R}^{2}=0,922$ ), em cada um dos pontos, nos diferentes períodos estudados. Os valores apresentam baixa dispersão (desvio padrão variando de 0,1 até 0,4 ), o que indica pouca variabilidade dos valores de vazão reconstruídos nos períodos, seco (JJA de 2010 e 2011) e úmido (DJFM de 2010/2011).

Tabela 7. Médias e desvio padrão dos dados de vazão reconstruídos $\left(\mathrm{m}^{3} \mathrm{~s}^{-1}\right)$ nos diferentes pontos e períodos de estudo.

\begin{tabular}{|c|c|c|c|c|}
\hline \multirow{2}{*}{ Pontos } & \multicolumn{4}{|c|}{$\operatorname{Vazão}\left(\mathrm{m}^{3} \mathrm{~s}^{-1}\right)$} \\
\hline & $\mathrm{P}_{1}$ & $\mathrm{P}_{3}$ & $\mathrm{P}_{4}$ & $\mathrm{P}_{5}$ \\
\hline & \multicolumn{4}{|c|}{ Período seco (JJA de 2010) } \\
\hline Média & 0,4 & 0,8 & 0,4 & 0,2 \\
\hline \multirow[t]{2}{*}{ Desvio Padrão } & 0,1 & 0,0 & 0,0 & 0,1 \\
\hline & \multicolumn{4}{|c|}{ Período úmido (DJFM de 2010/2011) } \\
\hline Média & 1,1 & 1,4 & 0,9 & 1,8 \\
\hline \multirow[t]{2}{*}{ Desvio Padrão } & 0,2 & 0,1 & 0,1 & 0,4 \\
\hline & \multicolumn{4}{|c|}{ Período seco (JJA de 2011) } \\
\hline Média & 0,4 & 0,8 & 0,5 & 0,3 \\
\hline Desvio Padrão & 0,0 & 0,0 & 0,0 & 0,1 \\
\hline
\end{tabular}


Em todo o período estudado foi feita a correlação (Coeficiente de Pearson) da vazão com os parâmetros de qualidade da água que foram medidos. Pela análise de variância (valor do teste F), observa-se que houve significância (ao nível de 1 e 5\% de probabilidade) dos modelos de regressão linear entre vazão e os parâmetros de qualidade da água em alguns pontos $(* *)$ (Tabela 8$)$.

A temperatura da água é o parâmetro mais influenciado pela sazonalidade da vazão (apresentando uma forte correlação positiva, $0,8 \leq \mathrm{r}<1$ ). A condutividade elétrica da água também apresenta maior tendência à correlação positiva (predomínio nos diferentes pontos de fraca/moderada correlação positiva, $0,1 \leq \mathrm{r}<0,5 / 0,5 \leq \mathrm{r}<0,8)$. No caso do $\mathrm{pH}$ e OD estes parâmetros apresentam maior tendência à correlação negativa (predomínio nos diferentes pontos de fraca/moderada correlação negativa, $-0,1 \leq \mathrm{r}<-0,5 /-0,5 \leq \mathrm{r}<-0,8)$. Estes resultados indicam que com um maior total precipitado (período úmido), pode-se esperar, um aumento da temperatura da água, uma leve tendência de aumento da condutividade e também uma leve tendência de diminuição do pH e OD. Este fato pode estar ligado ao aumento do escoamento superficial na área e desta maneira aumento da concentração de matéria orgânica e particulada dissolvidas no corpo d'água.

Tabela 8. Correlação de Pearson entre vazão e os parâmetros de qualidade da água (temperatura, potencial hidrogeniônico ( $\mathrm{pH}$ ), condutividade (condut.) e oxigênio dissolvido(OD)).

\begin{tabular}{l|cccc}
\hline Coeficiente de Pearson & $\mathrm{P}_{1}$ & $\mathrm{P}_{3}$ & $\mathrm{P}_{4}$ & $\mathrm{P}_{5}$ \\
Vazão x temperatura & $0,9^{* *}$ & $0,8^{* *}$ & $0,9 * *$ & $0,9 * *$ \\
Vazão x pH & $-0,5 * *$ & $-0,5^{* *}$ & 0,1 & $-0,1$ \\
Vazão x Condut. & 0,2 & $0,6 * *$ & $-0,2$ & $0,6^{* *}$ \\
Vazão x OD & $-0,4 * *$ & 0,2 & $-0,3$ & $-0,6 * *$ \\
\hline
\end{tabular}

**Significativo ao nível de 1 e $5 \%$ de probabilidade.

Reis et al. (2010) enfatizaram que bacias hidrográficas localizadas em montanhas desempenham um papel importante no transporte de sedimentos, pois possuem uma menor capacidade de armazenamento e uma resposta rápida a picos de precipitação, transportando cargas sedimentares significativas e respectivos poluentes associados, em períodos de tempo reduzidos. O escoamento da água sobre a camada superficial do solo durante os eventos pluviais é a principal fonte difusa de poluição nos mananciais hídricos (Vasco et al., 2011). Os sedimentos são componentes fundamentais do ambiente fluvial, providenciando nutrientes para os organismos vivos e atuando como depósito para muitos contaminantes de origem antrópica.

\section{CONCLUSÃO}

Com este estudo foi possível observar algumas tendências nos parâmetros de qualidade da água do Ribeirão dos Macacos. Sendo que estas tendências podem ser devido às práticas conservacionistas adotadas. Assim, foi observado aumento médio no potencial hidrogeniônico-pH e oxigênio dissolvido-OD, e no caso da condutividade elétrica um decaimento médio. Os dados observados são preliminares, mas já podem ser um indicativo da resposta da bacia às ações de recuperação iniciadas na área de monitoramento.

A temperatura da água, quando comparada aos parâmetros $\mathrm{pH}$, condutividade elétrica e OD, foi o parâmetro mais influenciado pela sazonalidade da vazão. Todavia, pode-se observar 
que em período chuvoso com o aumento do escoamento superficial e da vazão ocorreram aumento da temperatura da água, uma leve tendência de aumento da condutividade e uma leve tendência de diminuição do pH e OD.

Diante do exposto, este primeiro estudo de análise da qualidade e quantidade da água é um ponto de referência para que as ações de recuperação ambiental continuem sendo implantadas a fim de melhorar e recuperar a área, e consequentemente os corpos d' água desta região.

\section{AGRADECIMENTOS}

Agradecemos ao CNPq pela bolsa de mestrado concedida; ao CPTEC/INPE, Instituto Oikos de Agrecologia e FEHIDRO pelo apoio financeiro e disponibilização de dados para obtenção deste trabalho.

\section{REFERÊNCIAS}

AMERICAN PUBLIC HEALTH ASSOCIATION - APHA. Standard methods for examination of water and wastewater. 19. ed. Washington, 1995.

ARCOVA, F. C. S.; CICCO, V. Qualidade da água de microbacias com diferentes usos do solo na região de Cunha, Estado de São Paulo. Revista Scientia Forestalis, Piracicaba, n. 56, p. 125-134, 1999.

BOLSTAD, P. V.; SWANK, W. T. Cumulative impacts of landuse on water quality in a southern Appalachian watershed. Journal of the American Water Resources Association, Middleburg, v. 33, n. 3, p. 519-533, 1997. http://dx.doi.org/ 10.1111/j.1752-1688.1997.tb03529.x

BRASIL. Ministério do Meio Ambiente. Resolução no 357, de 17 março 2005. Dispõe sobre a classificação dos corpos de água e diretrizes ambientais para o seu enquadramento, bem como estabelece as condições e padrões de lançamento de efluentes, e dá outras providências. Brasília, 2005. 23 p.

BUENO, L. F.; GALBIATTI, J. A.; BORGES, M. J. Monitoramento de variáveis de qualidade da água do Horto Ouro Verde - Conchal - SP. Engenharia Agrícola, Jaboticabal, v. 25, n. 3, p. 742-748, set./dez. 2005. http://dx.doi.org/10.1590/S010069162005000300020

FISCH, G. Caracterização climática e balanço hídrico de Taubaté (SP). Revista Biociências, Taubaté, v. 1, n. 1, p. 81-90, 1995.

GOLLA, A. R. Meio ambiente e agricultura na microbacia hidrográfica do córrego Palmitalzinho - Regente Feijó / São Paulo. 2006. 90 f. Dissertação (Mestrado em Geografia) - Faculdade de Ciência e Tecnologia, Universidade Estadual Paulista, Presidente Prudente, 2006.

INSTITUTO OIKOS DE AGROECOLOGIA. Figuras - Lorena. [ca. 2009]. Disponível em: <http://www.institutooikos.org.br/instituto.html>. Acesso em: 10 dez. 2012.

LIMA, K. C.; SATYAMURTY, P.; FERNÁNDEZ, J. P. R. Large-scale atmospheric conditions associated with heavy rainfall episodes in southeast Brazil. Theoretical and Applied Climatology, v. 101, n. 1-2, p. 121-135, 2010. http://dx.doi.org/ 10.1007/s00704-009-0207-9 
MACHADO, A.; SILVA, M.; VALENTIM, H. Contributo para a avaliação do estado das massas de água na região norte. Revista Recursos Hídricos, Lisboa, v. 31, n.1, p. $57-$ 63, 2010.

MAIER, M. H. Ecologia da bacia do rio Jacaré-Pepira $\left(47^{\circ} 55^{\prime}-48^{\circ} 55^{\prime} \mathrm{W} ; 22^{\circ} 30^{\prime}-21^{\circ} 55^{\prime} \mathrm{S}\right.$ Brasil): qualidade da água do rio principal. Ciência e cultura, Campinas, v. 39, n. 2, p. 164-185, 1987.

MANANDHAR, S.; VOGT, D. S.; PERRET, S. R.; KAZAMA, F. Adapting cropping systems to climate change in Nepal: a cross-regional study of farmers' perception and practices. Regional Environmental Change, v. 1, n. 2, p. 335-348, 2011. http://dx.doi.org/10.1007/s10113-010-0137-1

MARENGO, J. A.; ALVES, L. M. Tendências hidrológicas da bacia do rio Paraíba do Sul. Revista Brasileira de Meteorologia, São José dos Campos, v. 20, n. 2, p. 215-226, 2005.

MOSLEY, M. P.; MCKERCHAR, A. L. Streamflow. In: MAIDMENT, D. R. Handbook of hydrology. New York: McGraw-Hill, 1993. cap. 8.

NEARY, D. G.; ICE, G. G.; JACKSON, C. R. Linkages between forest soils and water quality and quantity. Forest Ecology and Management, Elsevier, v. 258, n. 10, p. 2269-2281, 2009. http://dx.doi.org/10.1016/j.foreco.2009.05.027

REIS, A.; PARKER, A.; ALENCOÃO, A. Avaliação da qualidade de sedimentos em rios de montanha: um caso de estudo no norte de Portugal. Revista Recursos Hídricos, Lisboa, v. 31, n.1, p. 87-97, 2010.

SANTOS, C. Estatística descritiva: manual de auto-aprendizagem. 1. ed. Lisboa: Silabo, 2007. 264p.

SANTOS, A. G.; TARGA, M. S.; BATISTA, G. T.; DIAS, N. W. Florestamento compensatório com vistas à retenção de água no solo em bacias hidrográficas do município de Campos do Jordão, SP, Brasil. Revista Ambiente \& Água, Taubaté, v. 6, n. 3, 2011. http://dx.doi.org/10.4136/ambi-agua.490

SILVA, A. P. S.; DIAS, H. C. T.; BASTOS, R. K. X.; SILVA, E. Qualidade da água do Reservatório da Usina Hidrelétrica (UHE) de Peti, Minas Gerais. Revista Árvore, Viçosa, v. 33, n. 6, p. 1063-1069, 2009. http://dx.doi.org/10.1590/S010067622009000600009

SILVA, A. E. P.; ANGELIS, C. F.; MACHADO, L. A. T.; WAICHAMAN, A. V. Influência da precipitação na qualidade da água do Rio Purus. Acta Amazonica, v. 38, n. 4, p. 733-742, out./dez. 2008. http://dx.doi.org/10.1590/S0044-59672008000400017

VASCO, A. N.; BRITTO, F. B.; PEREIRA, A. P. S.; MÉLLO JÚNIOR, A. V. M.; GARCIA, C. A. B.; NOGUEIRA, L. C. Avaliação espacial e temporal da qualidade da água na sub-bacia do rio Poxim, Sergipe, Brasil. Revista Ambiente \& Água, Taubaté, v. 6, n. 1, p. 118-130, 2011. http://dx.doi.org/10.4136/ambi-agua.178 